\title{
UPAYA MENGONTROL PERILAKU AGRESIF PADA PERILAKU KEKERASAN DENGAN PEMBERIAN RATIONAL EMOTIVE BEHAVIOR THERAPY
}

\author{
Moomina Siauta $^{1 *}$ Hani Tuasikal $^{2}$, Selpina Embuai ${ }^{1}$ \\ ${ }^{1}$ Fakultas Ilmu Keperawatan Universitas Kristen Indonesia Maluku, Jln Ot Pattimaipauw, Talake \\ Kecamatan, Nusaniwe, Kel Wainitu, Nusaniwe, Kota Ambon, Maluku, Indonesia 97115. \\ ${ }^{2}$ Akper Rumkit TK III Dr. J. A. Latumeten Ambon, Jalan Dr. Tamaela No.2, Kel Silale, \\ Nusaniwe, Kota Ambon, Maluku, Indonesia 97111 \\ *moominasiauta@gmail.com
}

\begin{abstract}
ABSTRAK
Perilaku kekerasan merupakan salah satu jenis gangguan jiwa.WHO (2015) menyatakan, paling tidak ada satu dari empat orang di dunia mengalami masalah mental.Perilaku kekerasan merupakan salah satu penyakit jiwa yang ada di Indonesia, dan hingga saat ini diperkirakan jumlah penderitanya mencapai 2 juta orang, terutama dengan gejala perilaku agresif dan bila tidak tertangani dengan baik maka akan menimbulkan dampak yang buruk kepada klien serta lingkungannya, sehingga perlunya suatu tindakan keperawatan yang secara mandiri diberikan untuk menangani perilaku agresif itu sendiri yaitu dengan Terapi Ration Emotive Behavior. Jenis penelitian adalah dengan pendekatan studi kasu (Studi kasus).Pengumpulan data melalui observasi, wawancara mendalam, dokumentasi, dan bahan audio visual.Pengambilan sampel dengan menggunakan purposive sampling, dengan 6 klien perilaku kekerasan di RSKD Maluku.Penelitian dilakukan bulan Maret sampai dengan Oktober 2019.Jenis pengumpulan data yang dilakukan dengan wawancara dan lembar observasi klien.Lokasi penelitian RSKD Maluku.Sesuai dengan masalah yang peneliti angkat yaitu untuk mengontrol perilaku agresif dengan penerapan rational emotive behavior therapy dan SP yang telah diterapka, peneliti hanya menyusun intervensi terfokus pada masalah halusinasi pendengaran karena semua tindakan untuk mengontrol perilaku kekerasan juga dapat meminimalkan semua masalah keperawatan yang ada pada klien perilaku kekerasan.
\end{abstract}

Kata kunci: perilaku agresif, rational emotive behavior therapy

\section{EFFORTS TO CONTROL AGGRESSIVE BEHAVIOR IN VIOLENCE BEHAVIOR WITH RATIONAL EMOTIVE BEHAVIOR THERAPY}

\begin{abstract}
One type of mental disorder WHO states, at least one in four people in the world who fix mental problems. In Indonesia, and to date it is estimated that the number of sufferers reaches 2 million, most of the above mentioned are complex challenges and if not handled properly will cause problems for the client and his environment, so action is needed. Independent care is provided for Rational Therapy itself, namely Ration Emotive Behavior Therapy. This type of research is a case study study (case study). Data collection through collection, interview, collection, and audio-visual material.Sampling using purposive sampling, with 6 clients practicing violence in Maluku Regional General Hospital. This research was conducted from March to October 2019. Types of data collection were done by interview and client observation sheets. Research location of Maluku Regional Public Hospital. In accordance with the issues raised by researchers, namely for those who are related to therapy using emotive rational behavior therapy and SP that has been applied, researchers can only focus on interventions on the issue of delegation hallucinations to help change existing clients to overcome these problems.
\end{abstract}

Keywords: aggressive behavior, rational emotional behavior therap 


\section{PENDAHULUAN}

Perilaku kekerasan merupakan salah satu jenis gangguan jiwa.WHO (2015) menyatakan, paling tidak ada satu dari empat orang di dunia mengalami masalah mental.WHO memperkirakan ada sekitar 450 juta orang di dunia mengalami gangguan kesehatan jiwa. Pada masyarakat umum terdapat $0,2-0,8 \%$ penderita skizofrenia dan dari 120 juta penduduk di Negara Indonesia terdapat kirakira 2.400.000 orang anak yang mengalami gangguan jiwa (Maramis, 2014 dalam Carolina, 2015). Data WHO tahun 2006 mengungkapkan bahwa 26 juta penduduk Indonesia atau kira-kira 12-16 persen mengalami gangguan jiwa. Berdasarkan data Departemen Kesehatan, jumlah penderita gangguan jiwa di Indonesia mencapai 2,5 juta orang (WHO, 2016).

Menurut hasil survey Kesehatan Mental 2016 ditemukan 185 per 1000 penduduk di Indonesia menunjukan adanya gejala gangguan jiwa. Hal ini didukung data dari Depkes RI yang melaporkan bahwa di Indonesia jumlah penderita penyakit jiwa berat sekitar 6 juta orang atau sekitar 2,5\% dari total penduduk Indonesia. Perilaku kekerasan merupakan salah satu penyakit jiwa yang ada di Indonesia, dan hingga saat ini diperkirakan jumlah penderitanya mencapai 2 juta orang.Prevalensi pada pasien Perilaku Kekerasan di RSKD Maluku, selama 3 tahun terakhir yaitu tahun 2015 $(43,75 \%)$, 2016 (43,75\%), 2017 (12,5\%). Hal ini menunjukkan adanya penurunan angka kejadin perilaku kekerasan. Secara umum seseorang akan marah jika dirinya merasa terancam, baik berupa injury secara fisik, psikis, atau ancaman. Beberapa faktor pencetus perilaku kekerasan adalah sebagai berikut, rasa frustasi, kekerasan dalam rumah tangga, masa lalu yang tidak menyenangkan, kehilangan orang yang berarti, kehidupan yang penuh dengan agresif (Kusumawati et al, 2013).Berikut ini yang merupakan tanda dan gejala perilaku kekerasan diantarnya mata melotot, pandangan tajam, berbicara dengan nada keras, menyerang orang lain, wajah memerah dan tegang (Fitria, 2012).

Istilah marah (anger), agresif (aggression), dan perilaku kekerasan (violence) sering digunakan bergantian dalam menguraikan perilaku yang terkait dengan kekerasan (Rawlins, et, al 1993).Perilaku kekerasan merupakan suatu bentuk perilaku untuk melukai atau mencederai diri sendiri, orang lain, lingkungan secara verbal atau fisik (Stuart \& Laraia, 2015). Perilaku kekerasan berfluktuasi dari tingkat rendah sampai tinggi yaitu dari memperlihatkan permusuhan pada tingkat rendah sampai pada melukai dalam tingkat serius dan membahayakan (Stuart \& Laraia, 2001;2005; 2009). Proses perkembangan perilaku kekerasan, masih menjadi perdebatan antara nature vs nurture, dibawa sejak lahir atau diperoleh selama perkembangan. Menurut teori biopsikososial disebabkan oleh interaksi yang kompleks antara faktor biologik, psikologik dan sosiokultural (Kneisl; Wilson \& Trigoboff, 2014). Dari uraian diatas dapat dikatakan bahwa perilaku kekerasan adalah respon kemarahan yang maladaptif dalam bentuk perilaku menciderai diri sendiri, orang lain dan lingkungan sekitarnya secara verbal maupun nonverbal mulai dari tingkat rendah sampai tingkat tinggi.

Klien dengan perilaku kekerasan, individu merupakan orang yang ambigue, selalu dalam kecemasan, mempunyai penilaian yang negatif terhadap diri dan orang lain, ketidakmampuan untuk menyelesaikan masalah dengan baik sehingga perilaku kekerasan merupakan salah satu cara yang digunakan untuk menyelesaikan masalah. Perilaku kekerasan merupakan salah satu gejala yang menjadi alasan bagi keluarga untuk merawat klien di rumah sakit jiwa karena berisiko membahayakan dirinya dan orang lain (Keliat, 2013). Dari pernyataan tersebut dapat diketahui bahwa perilaku kekerasan adalah perilaku yang menakutkan dan membahayakan bagi dirinya, keluarga dan masyarakat sehingga mereka berusaha mencari pertolongan dengan membawa klien ke rumah sakit dan berharap selama mendapat pengobatan dan perawatan di rumah sakit perilaku klien berkurang atau berubah.

Intervensi secara umum yang dilakukan pada pasien dengan perilaku agresif / perilaku kekerasan bervariasi yang berada dalam rentang preventive strategies, Anticipatory Strategies, dan Containment Strategies (Stuart \& Laraia, 2015). Strategi pencegahan (preventive strategies), meliputi kesadaran diri, psikoedukasi pada klien, dan latihan asertif. Strategi antisipasi (Anticipatory Strategies) meliputi komunikasi, perubahan lingkungan, perilaku dan psikofarmaka. Kemarahan yang dapat mengancam 
keselamatan diri sendiri, orang lain dan lingkungan (kegawat daruratan psikiatri) yang tidak dapat dikontrol dengan terapi psikofarmaka maka perlu dilakukan strategi penahanan (containment Strategies) yang meliputi manajemen krisis, pembatasan gerak, dan pengikatan.

Klien dengan perilaku kekerasan mengalami perubahan respon kognitif berupa gangguan proses pikir yaitu gangguan dalam mempersepsikan sesuatu serta tidak mampu membuat alasan (Boyd \& Nihart, 1996). Respon kognitif merupakan hasil penilaian terhadap kejadian yang menekan, pilihan koping yang digunakan, reaksi emosional, fisiologis, perilaku dan sosial individu (Stuart \& Laraia, 2005). Setelah terjadi penilaian kognitif terhadap situasi, individu akan menampilkan respon afektif yang dimunculkan dengan emosi berupa marah, gembira, sedih, menerima, antisipasi atau respon emosi lainnya (Stuart \& Laraia, 2005). Pernyataan-pernyataan diatas dapat disimpulkan bahwa pada klien dengan perilaku kekerasan mengalami perubahan pada respon kognitif yang nantinya akan berpengaruh terhadap respon afektif yang dimunculkan dalam bentuk emosi seperti kemarahan. Hal ini menunjukkan bahwa intervensi yang diberikan pada klien dengan perilaku kekerasan juga perlu mengacu kepada emosi selain kognitif dan perilaku.

Berdasarkan teori tersebut maka perlu adanya intervensi pada klien dengan perilaku kekerasan yang mengarah kepada fisik, afektif (emosi), kognitif,fisiologis, perilaku, dan sosial. Terapi Asssertiveness Trainning, terapi Musik dan terapi Perilaku Kognitif belum mengarahkan intervensinya secara langsung kepada emosi klien dengan perilaku kekerasan. Untuk itu agar intervensi untuk klien dengan perilaku kekerasan lebih optimal maka perlu adanya suatu terapi yang juga mengarah pada emosi. Adapun terapi yang dapat dilakukan untuk itu adalah Rational Emotive Behaviour Therapy( REBT).

Rational Emotive Behavior Therapy (REBT) ditemukan oleh Albert Ellis, merupakan suatu pendekatan pemecahan masalah yang rasional, yang diarahkan untuk masalah perilaku individu. Elis berkeyakinan bahwa mempelajari kecemasan yang irrasional lebih awal akan bertahan di dalam memori manusia dari pada dihilangkan. Oleh karena itu beliau memutuskan untuk mengajarkan kliennya merubah pikiran yang tidak rasional (irrasional) dan memberikan penjelasan rasional untuk masalah perilakunya (Ellis, 1962 dalam Adomeh, 2006). Berdasarkan teori REBT memodifikasi keyakinan yang irrasional secara spesifik dapat menurunkan perilaku agresif. REBT dan treatmen lain bertujuan untuk mengurangi keyakinan irrasional dan menguatkan keyakinan rasional yang dapat efektif untuk anak dan dewasa yang marah dan agresif.

Hasil wawancara yang didapatkan di RSKD bahwa intervensi yang diberikan kepada pasien dengan perilaku kekerasannya hanya sebatas mengontrol amarah dengan melakukan kegiatan sehari-hari, untuk Rational Emotive Behavior Therapy tidak perna dilakukan oleh perawat. Rational Emotive Behavior Therapy (REBT) ditemukan oleh Albert Ellis, merupakan suatu pendekatan pemecahan masalah yang rasional, yang diarahkan untuk masalah perilaku individu. Elis berkeyakinan bahwa mempelajari kecemasan yang irrasional lebih awal akan bertahan di dalam memori manusia dari pada dihilangkan. Oleh karena itu beliau memutuskan untuk mengajarkan kliennya merubah pikiran yang tidak rasional (irrasional) dan memberikan penjelasan rasional untuk masalah perilakunya (Ellis, 1962 dalam Adomeh, 2006). Berdasarkan teori REBT memodifikasi keyakinan yang irrasional secara spesifik dapat menurunkan perilaku agresif. REBT dan treatmen lain bertujuan untuk mengurangi keyakinan irrasional dan menguatkan keyakinan rasional yang dapat efektif untuk anak dan dewasa yang marah dan agresif.

\section{METODE}

Pendekatan yang dipakai dalam penelitian ini hanya menggunakan pendekatan studi kasus.Metode pengumpulan datanya memakai observasi, wawancara mendalam, dokumentasi, dan bahan dokumentasi perilaku (lembar obesrvasi) yang dilakukan pada bulan maret sampai dengan oktober 2019. Teknik samplingnya menggunakan purposive sampling, dengan subyek pnelitiannya 6 pasien dengan perilaku kekerasanyang dirawat di RSKD Maluku.

\section{HASIL}

Hasil asuhan keperawatan yang telah dilakukan pada klien dengan perilaku 
kekerasan dengan resiko perilaku kekerasan pendengaran dalam upaya mengontrol perilaku agresif dengan pemberian terapi rational emotive behavior therapy berfokus pada masalah perilaku kekerasan yang diderita klien, semua tindakan dalam penatalaksanaan yang sudah dibahas pada konsep teori dasar keperawatan jiwa Keliat, 2013 mengarah pada masalah halusinasi. Maka bagian ini peneliti akan membahas tentang kesenjangan antara teori yang ada dan kenyataan yang diperoleh sebagai hasil pelaksanaan studi kasus yang mengacuh pada tahap-tahap prosese keperawatan. Beberapa kesenjangan tersebut adalah sebagai berikut :

Sumber data yang diperoleh pada pengkajian yaitu didapat dari klien dan juga tambahan dari tim medis yaitu perawat. Peneliti tidak mendapatkan masalah yang berarti dalam hal pengkajian dalam mendapatkan data tentang masalah perilaku kekerasan. Pada pengkajian, data-data yang diperoleh khusus menyangkut masalah perilaku kekerasan adalah data hasil wawancar dan informasi dari status klien, informasi dari tim medis yang mendukung peneliti dalam pelaksanaan penelitian. Dilihat dari teori dan hasil pengkajian, semua tanda dan gejala dari masalah perilaku kekerasan yang ada pada teori ditemukan pada Klien perilaku kekerasan.Jadi temukan adannya kesenjangan antara teori dan kondisi klien pada saat pengkajian.

Diagnosa keperawatan yang muncul yaitu : Resiko perilaku kekerasan, Gangguan konsep diri : Harga Diri Rendah, Mekanisme koping individu dan keluarga inefektif. Berdasarkan hasil penelitian yang dilakukan, peneliti hanya memfokuskan pada satu masalah yaitu perilaku kekerasan. Karena sesuai dengan masalah yang peneliti angkat yaitu mengenai bagaimana terapi okupaasi pemberian rational emotive behavior therapy untuk mengontrol perilaku agresif dan juga tidak mengabaikan diagnose yang lain terkait dengan kondisi klien saat pengkajian, semua tindakan dalam upaya mengatasi perilaku kekerasan klien ada pada tindakan keperawatan (SP klien dan SP Terapi) dalam diagnose halusinasi, sehingga peneliti hanya memfokuskan pada masalah (diagnose keperawatan) halusinasi pendengaran.

\section{PEMBAHASAN}

Sesuai dengan masalah yang peneliti angkat yaitu untuk bagaimana klien dapat mengontrol halusinasi yang dirasakan dengan penerapan terapi rational emotive behavior therapy, maka sesuai dengan hasil penelitian, peneliti hanya menysusun intervensi terfokuskan pada masalah perilaku kekerasan karena semua tindakan untuk meningkatkan akitivitas klien agar perilaku kekerasan yang dirasakan dapat diminimalkan, bahkan perilaku agresifnya menghilang ada pada teori dan tindakan keperawatan dalam diagnose perilaku kekerasan namun peneliti juga tidak mengabaikan perencanaan tindakan keperawatan untuk masalah (diagnose keperawatan) lain yang ada pada klien.

Dalam pelaksanaan tindakan keperawatan, peneliti menggunkan strategi pelaksanaan (SP/Terapi) yang berfokus penerapan terapi rational emotive behavior therapy untuk mengontrol perilaku agresifnya yang dirasakan oleh klien, serta mengevaluasi jadwal kegiatan klien selama 3 hari dalam mengisi aktifitas luang dengan terapi rational emotive behavior therapy. Serta tidak mengabaikan SP yang lain, yaitu mengajarkan klien tentang cara berkenalan dengan orang lain, serta memasukkannya ke dalam jadwal kegiatan harian klien. Secara teoritis, tindakan yang dilakukan dalam upaya mengontrol perilaku agresif dengan penerapan terapi rational emotive behavior therapy, serta tindakan strategi lainnya yaitu penerapan strategi pelaksanaan (SP 1) bina hubungan saling percaya dengan klien, berjabat tangan dan duduk bersama, mengajarkan klien tentang cara berkenalan dengan orang lain, menjelaskan tentang kerugian dan keuntungan berinteraksi dengan orang lain, dan mengajurkan klien untuk memasukkan ke dalam jadwal kegiatan hariannya sehingga tercapainya SP I . Dilanjutkan pada SP II klien dapat berkenalan dengan orang lain dan menunjukan tercapainya SP II tersebut. Berdasarkan hasil penelitian, upaya mengontrol perilaku kekerasan yaitu perilaku agresif dengan terapi rational emotive behavior therapy, semuanya dilakukan berdasarkan teori yang ada, jadi terdapat kesenjangan antara teori dan hasil pelaksanaan pada penelitian.

Sesuai dengan hasil evaluasi yang didapatkan upaya untuk mengontrol perilaku agresifnya dengan terapi rational emotive behavior 
therapy pada klien perilaku kekerasan menunjukan adanya kemajuan dalam hal ini adalah semua jadwal telah di diisi dengan rational emotive behavior therapy sesuai dengan kesepakatan antara klien dengan peneliti, serta juga sudah tidak lagi terlihat berbicara sendiri, dank lien juga dapat berinteraksi serta meningkatan ketrampilan pada klien dengan peneran SP tersebut. Ini adalah hasil yang didapatkan peneliti saat melakukan penelitian pada klien perilaku kekerasan. Dengan demikian, antara teori dan hasil penelitian ditemukan adanya kesenjangan.

Penelitian lain terkait efektifitas rational emotive behavior therapy yaitu penelitian yang pernah dilakukan David, Szentagotai, Lupu, Cosman (2008) menyatakan bahwa rational emotive behavior therapy mampu menurunkan tingkat depresi pasien. Penelitian Warren (2010) juga menjelaskan bahwa rational emotive behavior therapy tampaknya memberikan kerangka kerja yang mendukung untuk meningkatkan kemanjuran guru dan potensi prestasi siswa.

\section{SIMPULAN}

Sesuai dengan masalah yang peneliti angkat yaitu untuk mengontrol perilaku agresif dengan penerapan terapi rational emotive behavior therapy dan SP yang telah diterapka, peneliti hanya menyusun intervensi terfokus pada masalah halusinasi pendengaran karena semua tindakan untuk mengontrol perilaku kekerasan juga dapat meminimalkan semua masalah keperawatan yang ada pada klien perilaku kekerasan

Sesuai dengan hasil evaluasi yang didapatkan adanya hasil yaitu dengan di masukkan jadwal meminum obat pada klien sesuai dengan ketentuan yang telah di tentukan, dan adanya peningkatan interaksi klien dengan orang lain. Dengan demikikan klien dengan perilaku kekerasan menunjukan tercapainya criteria intrevensi yang diaharapkan, yaitu berkurangnya dan dapat dikontrolnya perilaku kekerasan yang dirasakan klien.

\section{DAFTAR PUSTAKA}

Ali, Rameez. (2007). Application of REBT with Muslim clients.The Rational EmotiveBehaviour Therapist.Vol 12 No. 1. 3-8

Andrews, Bonta \& Wormith.(2004). Resilience and youth criminality.(Online). Tersedia: http: //www.p publicsafety.gc.ca (diakses: 24-102019).

Baron, A.E. Byrne D., \& Brascombe, R.N. 2006. Social Psychology (7thed). USA: Reason Education Inc.

Campbell, J. D. (1953). Manic Depressive Disease: Clinical and Psychiatric Significance. Oxford, England: Lippincott

Cresweell, John W. 2012. Research Design: Pendekatan Kualitatif, Kuantitatif dan Mixed (edisi ketiga). Yogyakarta: Pustaka Pelajar.

David, D., Szentagotai, A., Lupu, V., \& Cosman, D. (2008). Rational emotive behavior therapy, cognitive therapy, and medication in the treatment of major depressive disorder: a randomized clinical trial, posttreatment outcomes, and six-month follow-up. Journal of clinical psychology, 64(6), 728-746.

Davidof, Linda, L. 1991. Psikologi Suatu Pengantar. Edisi Kedua. Jakarta: Erlangga

Davison, Gerald C, John M. Neale, dan Ann M. Kring. 2012. Psikologi Abnormal Edisi ke-9. Depok: PT Rajagrafindo Persada

Dryden, W. \& Branch, R. (2008). The Fundamentals of Rational Emotive Behaviour Therapy: A Training Handbook. 2nd Ed. West Sussex: John Wiley \& Sons Inc.

Ellis, Albert \& Dryden, Windy. 1973. The Practice of Rational Emotive Behavior Therapy. New York :Springer Publishing

Ellis, Albert Ph.D. 2007. Terapi REB: Agar Hidup Bebas Derita. Terjemahan Ikramullah Mahyuddin. Yogyakarta: Penerbit B-First

Faizal, E.B. (2012). Psychiatrist links depression and heart disease. (http://www.thejakartapost.com/news/ 2012/10/06/psychiatrist-links- 
depression-andheart-disease.html, diakses 20 Oktober 2019)

Gilbert, P. (2001). Overcoming Depression: A Step-By-Step Approach To Gaining Control Over Depression. 2 nd Edition.Oxford University Press.

Hakim, M Arief. 2009. Bahaya Narkoba Alkohol: Cara Islam Mencegah, Mengatasi dan Melawan. Bandung: Nuansa

Saleebey, Dennis 2005. The Strengths Perspective in Social Work Practice. (4thed.). New York: Addison Wesley Longmans Publiser

Undang-Undang R.I Nomor 5 Tahun 1997 tentang Psikotropi

Warren, J. M. (2010). The Impact of Rational Emotive Behavior Therapy on Teacher Efficacy and Student Achievement. Journal of School Counseling, 8(11), n11.

Zamzami, A. 2007.Agresivitas Siswa SMK DKI Jakarta. Jurnal Pendidikan dan Kebudayaan, Tahun ke-13, Nomor 069 